\title{
Continuing impacts on red deer from a volcanic eruption in 2011
}

\author{
Werner T. Flueck
}

Received: 29 March 2014 / Revised: 30 April 2014 / Accepted: 2 May 2014

(C) Springer-Verlag Berlin Heidelberg 2014

\begin{abstract}
In June of 2011, the Puyehue-Cordon Caulle volcanic eruption deposited large amounts of ashes in Chile and Argentina. Although ashes were initially considered innoxious based on water leachates, we found clinical cases of fluoride intoxication in red deer (Cervus elaphus) and domestic herbivores in Argentina. The diagnosis was corroborated by high bone fluoride concentrations. The dynamics of temporal accumulation of fluoride suggested an average increase of 1,000 ppm per year of fluoride in the bone. However, a few deer had fluoride levels, suggesting an accumulation rate of about 3,700 ppm per year. Via recent sampling of deer, we now confirm that bone levels have reached up to $10,396 \mathrm{ppm}$ of fluoride after about 28 months of exposure. Tephra across various sites averaged $548 \mathrm{ppm}$ of fluoride, and due to dry conditions and eolic redeposition of ashes particularly east of the continental divide, clinical fluorosis is expected to continue to intensify. The described impact will reverberate through several aspects of the ecology of the deer, including effects on population dynamics, morbidity, predation susceptibility, as well as other components of the ecosystem, including other herbivores, scavengers, and plant communities.
\end{abstract}

Communicated by C. Gortázar

W. T. Flueck

National Council of Scientific and Technological Research

(CONICET), Buenos Aires, Argentina

W. T. Flueck $(\bowtie)$

Argentine National Park Administration, C.C. 592, 8400 Bariloche,

Argentina

e-mail: wtf@deerlab.org

W. T. Flueck

Swiss Tropical and Public Health Institute, University of Basel, Basel, Switzerland
Keywords Cervus elaphus $\cdot$ Fluorosis $\cdot$ Pathology $\cdot$ Red deer $\cdot$ Tephra $\cdot$ Volcanic eruption

\section{Introduction}

The Puyehue-Cordon Caulle volcanic eruption (PCCVE of June 2011, reviewed by Flueck and Smith-Flueck 2013a) deposited an estimated 100 million tons of tephra (ejected solid matter) over parts of Chile and over 36 million ha in Argentina, with winds depositing layers of tephra 5-cm thick at $240 \mathrm{~km}$ of distance (Fig. 1a). Volcanic eruptions can emit toxic levels of fluoride, which may impact animals in the surroundings (Cronin et al. 2000, 2003), yet fluorosis in wildlife raised concerns only relatively recently (Robinette et al. 1957; Karstad 1967) and principally regarding industrial pollution or use of fertilizers (Kierdorf et al. 1996a; Richter et al. 2010). A recent local example was the Lonquimay volcano eruption (1988, $200 \mathrm{~km}$ north of PCCVE), where fluorosis in livestock occurred within weeks (Araya et al. 1990). Immediately after the PCCVE, analyses of tephra revealed mainly $\mathrm{O}, \mathrm{Si}, \mathrm{Al}, \mathrm{Fe}, \mathrm{Na}$, and $\mathrm{K}$. Although initial concern was about intoxication with fluoride, based on incidences from other Chilean volcanoes, only fluoridecontaining microbubbles that may turn into fluorohydric acid upon contact with water were mentioned in tephra from Argentina (Bermúdez and Delpino 2011). Moreover, watersoluble extracts from tephra revealed low fluoride levels (0.7 ppm) (Hufner and Osuna 2011), surface water analyses from both countries revealed low fluoride levels, and overall water consumption was considered without risk for humans and animals (DGA 2012; Wilson et al. 2013). Initial livestock losses in the region were high but attributed to inanition, rumen blockage, and excessive tooth wear, rather than to known toxic elements (Wilson et al. 2013). Given the recent regional example of the Lonquimay volcano eruption, where 


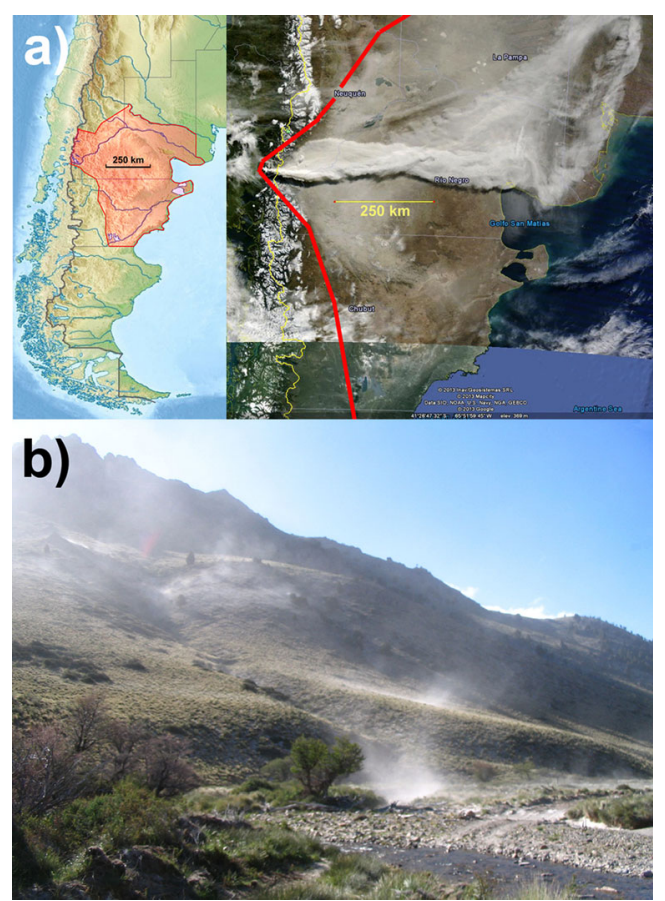

Fig. 1 a Distribution of tephra deposited from the Puyehue-Cordon Caulle volcanic eruption, showing the Moderate Resolution Imaging Spectroradiometer image of 13 June 2011, http://earthobservatory.nasa. gov. The red line marks the limit of deposition, principally in the Provinces of Neuquen, Rio Negro, and Chubut. b Ecotonal landscape in the Patagonian study area. Although known for commonly strong eolic conditions, this was a "calm day without westerlies: This turbulence is due to daily thermal wind patterns which shift ashes in any direction (color figure online)

fluorosis in livestock occurred within weeks, we began by investigating whether wild red deer (Cervus elaphus) were affected from exposure to tephra from the PCCVE.

Deer sampled in September-October 2012 at $100 \mathrm{~km}$ from the volcanic eruption revealed that these tephra caused severe dental fluorosis in developing dentitions, with the associated loss of teeth functionality affecting the physical condition, with none of the subadults being able to conceive (Flueck and Smith-Flueck 2013a). We next considered whether our results from red deer were reflected by similar evidence in livestock. We found that bone fluoride levels reached similar high levels in livestock including sheep, cattle, and horses, from samples stemming as far as $222 \mathrm{~km}$ from the volcano. Fluorosis was associated with pathologic wear of newly emerging teeth and extremely rapid ablation of entire crowns down to underlying pulp cavities (Flueck 2013). Moreover, our analysis of tephra from several sites revealed their high average total level of $548 \mathrm{ppm}$ of fluoride, being several-fold higher than fluoride in tephra from the Mount St. Helens eruption in 1980 (Taves 1980).

Given that the tephra accumulation increases toward the volcano (Wilson et al. 2013), with prevailing winds principally coming from there, the resulting downwind redeposition was predicted to last numerous years (Flueck and Smith-
Flueck 2013b). This process is facilitated by the dry climatic condition which retards the incorporation of tephra into the soil. Moreover, redeposition rates are affected by animal trampling, burrowing, rooting, and dry summers such that the commonly strong eolic conditions redistribute tephra further downslope and downwind (Fig. 1b).

The Patagonian huemul deer (Hippocamelus bisulcus) was reported to frequently exhibit osteopathology, with a prevalence of $57 \%$ among adults (Flueck and Smith-Flueck 2008). Biological agents as the primary cause appeared unlikely, and fluorosis was discarded due to lack of known clinical cases in those areas. Rather, we hypothesized that trace mineral deficiencies may play a key role. As the pathophysiognomy had important resemblances to fluorotic cases, we analyzed bone tissue from affected huemul to find, however, that fluoride concentrations were very low.

To gain further insight into the dynamics of fluoride accumulation in the bone of red deer exposed to the tephra, we determined the accumulation rates beginning from the fetal stage. Whereas mothers already averaged 2,151 ppm, their late-term fetuses had only $19.8 \mathrm{ppm}$, indicating a barrier to fluoride transport in utero (Flueck and Smith-Flueck 2013b), in agreement with previous evidence that prenatal to preweaning stages of dental development are protected against exposure to excess fluoride in the mothers (Robinette et al. 1957; Richter et al. 2011). Levels among older deer reached an average of 2,806 ppm (maximum 5,175 ppm), and the average annual increase among four age classes was about 1,000 ppm per year, with one individual having accumulated about 3,700 ppm per year. As predicted here, I report that wild deer not only continued to accumulate fluoride but also that maximal bone concentrations have exceeded 10,000 ppm after about 28 months of exposure.

\section{Material and methods}

Female deer were collected during October and November of 2013 in the National Reserve, Nahuel Huapi National Park, province of Neuquén, Argentina $\left(41.027^{\circ} \mathrm{S}, 71.157^{\circ} \mathrm{W}\right)$. Samples from huemul deer from areas outside of the tephra deposits were analyzed for fluoride concentrations along with the bone samples of calves, subadult, and adult red deer. Samples were obtained from mandibles by removing about $1 \mathrm{~g}$ from the ventral ridge at the level of molar M1. Fluoride concentrations were determined in the Laboratorio de Biología Ósea (Universidad Nacional de Rosario, Argentina) (Rigalli et al. 2007). Samples were first ashed at $550{ }^{\circ} \mathrm{C}$, and then acid labile fluorine was isolated from $50 \mu \mathrm{g}$ of the sample by isothermal distillation and the sample treated with phosphoric acid $98 \% w / w$ at $60{ }^{\circ} \mathrm{C}$ for 1 day. During this time, hydrofluoric acid released from samples was recovered by sodium hydroxide placed in the cup of the distillation 
chamber. Subsequently, the sodium hydroxide trap was adjusted to $\mathrm{pH} 5.5$ with acetic acid $17.5 \mathrm{~mol} / \mathrm{l}$. Standards ranging from $10^{-3}$ to $10^{-6} \mathrm{~mol} / \mathrm{l}$ were simultaneously processed. Total fluoride was measured by direct potentiometry using an ion selective electrode ORION 94-09 and a reference electrode of $\mathrm{Ag} / \mathrm{AgCl}$. Duplicate samples were analyzed, resulting in coefficients of variation of $<6 \%$, and the results are presented as the mean, expressed as part per million in dry bone.

\section{Results}

The red deer sample revealed fluoride levels which increased on average with advancing age and thus exposure time. Eolic conditions lead to a nonhomogeneous distribution of tephra, which is reflected in the variation of bone fluoride levels among deer stemming from a given area. On average, yearling deer had $688 \mathrm{ppm}$ of fluoride ( $\mathrm{SE}=60.1$, range $598-802, n=$ 3 ), 2-year-old averaged 1,310 ppm of fluoride (range 714$1,905, n=2)$, whereas 3 -year-old and older averaged $4,014.5 \mathrm{ppm}(\mathrm{SE}=2148$, range $1,100-10,396, n=4)$. The average annual accumulation rate of $1,283 \mathrm{ppm}$ is similar to the one reported earlier (Flueck and Smith-Flueck 2013b), indicating that the prediction of annual accumulation of fluoride continues. Whereas the maximal value reported earlier reached 5,175 ppm by November 2012 (Flueck and SmithFlueck 2013b), one adult deer having been exposed continuously to tephra has now reached a bone fluoride level of $10,396 \mathrm{ppm}$ by the end of October 2013. Whereas the earlier maximal value represents an annual accumulation rate of about 3,700 ppm, this latest maximal value represents an annual accumulation rate of about $4,455 \mathrm{ppm}$. The prevailing strong influence of tephra is also revealed in the pronounced increases of bone fluoride levels in younger age classes. An age-dependent increase in bone fluoride levels has also been documented in red deer in contaminated areas of Europe (Kierdorf et al. 1996b).

Fluoride levels in the bones of huemul stemming from areas not affected by this recent volcanic event, but affected by osteopathology, averaged $58 \mathrm{ppm}(\mathrm{SE}=10.7, n=5$, range 14-107 ppm).

\section{Discussion}

The landscape is heterogeneous regarding the vegetation, principally resulting from the precipitation pattern induced from the orography of the Andes. Additionally, there is much variation in the topography which influences eolic conditions and therefore deposition patterns of volatile particles. As red deer establish permanent home ranges which are rarely altered among adults, different deer may inhabit areas with quite distinct levels of exposure to tephra. Hence, although in close proximity regarding distance, nearby deer may be exposed to quite different scenarios of contamination by tephra, apart from individual differences in feeding habits. This may be the most parsimonious explanation for the variability in bone fluoride levels within an age class encountered in the deer population.

As osteofluorosis occurs in deer with $>4,000 \mathrm{ppm}$ in dry bone (Schultz et al. 1998), the accumulation to $10,396 \mathrm{ppm}$ in an approximately 6-7-year-old deer in about 28 months raises the possibility of imminent clinical expression of osteopathology. Importantly, the impact from fluoride may be further exacerbated by the region being iodine deficient with endemic goiter rates of 50-80\% in 1965, before iodized salt was introduced (Salvaneschi and García 2009). Epidemiologic and experimental data show that iodine deficiency increases the incidence of dental fluorosis and severity of damages caused by excessive fluoride and also increases bone fluoride content (Xu et al. 1994; Zhao et al. 1998; NRC 2006). Lastly, based on clinical and biochemical symptoms, the region is deficient in selenium, with well-known negative impacts on iodine metabolism (Flueck and Smith-Flueck 2008, 2011; Flueck et al. 2014).

The low fluoride levels in huemul were comparable to concentrations in antlers from red deer hunted before the 2011 volcanic eruption which averaged $63 \mathrm{ppm}(\mathrm{SE}=10.7$, range 34-92 ppm) (Flueck and Smith-Flueck 2013a). In Europe, fluoride levels in antlers collected before 1860 (prior to major industrial pollution) ranged from 18 to $50 \mathrm{ppm}$ and were considered natural baseline levels (Kierdorf and Kierdorf 2000). Given the absence of industry throughout the region, results demonstrate that fluoride levels are normally at low nontoxic levels, and therefore, fluorosis has not been a causal factor in osteopathology reported in huemul (Flueck and Smith-Flueck 2008).

The average concentration of fluoride in tephra from ten different sites was 548 ppm (range 491-620 ppm, unpublished). This is rather high and explains the occurrence of fluorosis among herbivores in the affected area. The rapid rate of fluoride accumulation in the bone documented here coincides with observations in other cervids in contaminated environments (Kierdorf and Kierdorf 2002) or in feeding experiments (Suttie et al. 1985).

Although fluoride in our study area continues to accumulate in red deer and likely in bovids and equids causing overt pathology, the effects on the native camelid Lama guanicoe remain unstudied. These findings have major implications for the region affected by the PCCVE. The described impact will reverberate through several aspects of the ecology of the deer, including effects on population dynamics, morbidity, predation susceptibility, as well as other components of the ecosystem, including other herbivores, scavenger, and plant communities. For instance, Garrott et al. (2002) found that the onset of survival 
senescence in nonaffected deer occurred at about 16 years of age with a life expectancy of 25 years, whereas none of the deer with bones averaging 1,711 ppm of fluoride survived beyond 16 years: Accordingly, there was a $24 \%$ reduction in the potential annual population growth rate.

Acknowledgments This research was done on private land within a natural reserve of the Argentine Administración de Parques Nacionales (permit 070-2013) with partial funding stemming from the PIP CONICET grant Nr. 11220110100124. The authors are grateful to Juan Jones, Konrad Bailey and Pio Pigorini, Lalo Martinez, and Ricky Aquirre for facilitating access and allowing us to work on their properties. Logistics were provided by DeerLab, Argentina, and we also thank Swazi New Zealand for protective field garments, Rubén Kodjaian for providing our office with crucial logistics via the Hostería El Retorno, and Beat Fuchs for his dedicated field assistance within clouds of tephra. I thank the two reviewers for very constructive comments.

\section{References}

Araya O, Wittwer F, Villa A, Ducon C (1990) Bovine fluorosis following volcanic activity in the Southern Andes. Vet Rec 126:641-642

Bermúdez A, Delpino D (2011) La actividad el volcan Puyehue y su impacto sobre el territorio de la república Argentina. Primer Informe, Neuquén, CONICET. http://medicina.uncoma.edu.ar/ download/academica/impacto_de_la_actividad_del_volcan_ puyehue.pdf Accessed 1 November 2012

Cronin SJ, Manoharan V, Hedley MJ, Loganathan P (2000) Fluoride: a review of its fate, bioavailability, and risks of fluorosis in grazed pasture systems in New Zealand. NZ J Agr Res 43:295-321

Cronin SJ, Neall VE, Lecointre JA, Hedley MJ, Loganathan P (2003) Environmental hazards of fluoride in volcanic ash: a case study from Ruapehu volcano, New Zealand. NZ J Volcanol Geotherm Res 121: 271-291

DGA (Dirección General de Aguas) (2012) Informa resultados del programa de monitoreo de emergencia por erupción volcánica en Cordón Caulle. Minuta 7, Ministerio de Obras Publicas, Santiago, Chile. http://documentos.dga.cl/CQA5306.pdf Accessed 1 November 2012

Flueck WT (2013) Effects of fluoride intoxication on teeth of livestock due to a recent volcanic eruption in Patagonia, Argentina. Onl J Vet Res 17:167-176

Flueck WT, Smith-Flueck JM (2008) Age-independent osteopathology in skeletons of a south American cervid, the Patagonian huemul (Hippocamelus bisulcus). J Wildl Dis 44:636-648

Flueck WT, Smith-Flueck JM (2011) Recent advances in the nutritional ecology of the Patagonian huemul: implications for recovery. Anim Prod Sci 51:311-326

Flueck WT, Smith-Flueck JM (2013a) Severe dental fluorosis in juvenile deer linked to a recent volcanic eruption in Patagonia. J Wildl Dis 49:355-366

Flueck WT, Smith-Flueck JM (2013b) Temporal kinetics of fluoride accumulation: from fetal to adult deer. E J Wildl Res 59:899-903

Flueck WT, Smith-Flueck JM, Mincher BJ, Winkel LHE (2014) An alternative interpretation of plasma selenium data from endangered Patagonian huemul deer (Hippocamelus bisulcus). J Wildl Dis, accepted

Garrott RA, Eberhardt LL, Otton JK, White PJ, Chaffee MA (2002) A geochemical trophic cascade in Yellowstone's geothermal environments. Ecosystems 5:659-666
Hufner R, Osuna CM (2011) Caracterización de muestras de cenizas volcánicas volcán Puyehue. Doc. C289-CCGG-9IPCA-001-A, INVAP S.E., Bariloche, Argentina. http://organismos.chubut.gov. ar/ambiente/files/2011/06/Informe-Cenizas-Puyehue1.-INVAP.pdf Accessed 1 November 2012

Karstad L (1967) Fluorosis in deer (Odocoileus virginianus). Bull Wildl Dis Assoc 3:42-46

Kierdorf U, Kierdorf H (2000) The fluoride content of antlers as an indicator of fluoride exposure in red deer (Cervus elaphus): a historical biomonitoring study. Arch Environ Contam Toxicol 38: $121-127$

Kierdorf U, Kierdorf H (2002) Assessing regional variation of environmental fluoride concentrations in western Germany by analysis of antler fluoride content in roe deer (Capreolus capreolus). Arch Environ Contam Toxicol 42:99-104

Kierdorf U, Kierdorf H, Sedlacek F, Fejerskov O (1996a) Structural changes in fluorosed dental enamel of red deer (Cervus elaphus L.) from a region with severe environmental pollution by fluorides. $\mathrm{J}$ Anat 188:183-195

Kierdorf H, Kierdorf U, Sedlacek F, Erdelen M (1996b) Mandibular bone fluoride levels and occurrence of fluoride induced dental lesions in populations of wild red deer (Cervus elaphus) from central Europe. Environ Pollut 93:75-81

NRC (National Research Council) (2006) Fluoride in drinking water: a scientific review of EPA's standards. National Academies, Washington DC

Richter H, Kierdorf U, Richards A, Kierdorf H (2010) Dentin abnormalities in cheek teeth of wild red deer and roe deer from a fluoride-polluted area in Central Europe. Ann Anat 192:86-95

Richter H, Kierdorf U, Richards A, Melcher F, Kierdorf H (2011) Fluoride concentration in dentine as a biomarker of fluoride intake in European roe deer (Capreolus capreolus) - an electronmicroprobe study. Arch Oral Biol 56:785-792

Rigalli A, Pera LI, Di Loreto V, Brun LR (2007) Determinación de la concentración de flúor en muestras biológicas. Editorial de la Universidad Nacional de Rosario, Rosario

Robinette WL, Jones DA, Rogers G, Gashwiler JS (1957) Notes on tooth development and wear for Rocky Mountain mule deer. J Wildl Manag 21:134-153

Salvaneschi JP, García JR (2009) El bocio endémico en la República Argentina. Antecedentes, extensión y magnitud de la endemia, antes y después del empleo de la sal enriquecida con yodo. Segunda parte. Rev Arg Endocrinol Metabol 46:35-57

Schultz M, Kierdorf U, Sedlacek F, Kierdorf H (1998) Pathological bone changes in the mandibles of wild red deer (Cervus elaphus L.) exposed to high environmental levels of fluoride. J Anat 193:431442

Suttie JW, Hamilton RJ, Clay AC, Tobin ML, Moore WG (1985) Effects of fluoride ingestion on white-tailed deer (Odocoileus virginianus). J Wildl Dis 21:283-288

Taves DR (1980) Fluoride distribution and biological availability in the fallout from Mount St. Helens, 18 to 21 May 1980. Science 210: $1352-1354$

Wilson TM, Stewart C, Bickerton H, Baxter P, Outes AV et al (2013) Impacts of the June 2011 Puyehue-Cordón Caulle volcanic complex eruption on urban infrastructure, agriculture and public health. GNS Sci Rep 2012(20):1-88

Xu Y, Lu C, Zhang X (1994) The effect of fluoride on the level of intelligence in children. Endemic Dis Bull 9:83-84

Zhao W, Zhu H, Yu Z, Aoki K, Misumi J, Zhang X (1998) Long-term effects of various iodine and fluorine doses on the thyroid and fluorosis in mice. Endocr Regul 32:63-70 